\title{
Ultrasonographic contrast agents versus sonoelastography in digestive diseases
}

\author{
Modesto Varas-Lorenzo ${ }^{1}$, Fernando Muñoz-Agel ${ }^{1}$, Esteban Cugat-Andorra ${ }^{1}$ and Joan Gornals-Soler ${ }^{1,2}$ \\ ${ }^{1}$ Unit of Echo-Doppler and Echoendoscopy, and Digestive Surgery. Centro Médico Teknon. Barcelona. Spain. \\ ${ }^{2}$ Unit of Digestive Echoendoscopy (Department of Digestive Diseases). Hospital Universitario de Bellvitge. \\ Hospitalet de Llobregat. Barcelona, Spain
}

\begin{abstract}
A review is made of the indications of ultrasonographic contrast enhancement as applied to conventional ultrasonography and endocopic ultrasonography (EUS) as opposed to the use of EUS-sonoelastography today.
\end{abstract}

Key words: Ultrasonographic contrast media. Contrast-enhanced echoendoscopy. Elastography. Endoscopic sonoelastography. Echoendoscopy with sonoelastography. Neuroendocrine tumors. Pancreatic cancer. Chronic pancreatitis.

Varas Lorenzo Modesto, Muñoz Agel Fernando, Cugat Andorra Esteban, Gornals Soler Joan. Ultrasonographic contrast agents versus sonoelastography in digestive diseases. Rev Esp Enferm Dig 2011; 103: 204-208.

\section{INTRODUCTION}

Gastrointestinal real-time, gray-scale ultrasonography (US) has reached high resolution, performance, and sensitivity in the study of biliary, hepatosplenic, pancreatic, and even gastrointestinal (GI) tract conditions. It was then supplemented by color Doppler (CD) and power Doppler or color angiosonography, and more recently by contrast-enhancement (CE) (Gómez, 2007) and three dimensions (3-D) (Muñoz, 2007) in our country (1).

Received: $28-11-10$

Accepted: 16-12-10

Correspondence: M.J. Varas Lorenzo. Unidad de Eco-Doppler y Ecoendoscopia. Centro Médico Teknon. C/ Marquesa Vilallonga, 12. 08017 Barcelona. Spain

e-mail: varas@dr.teknon.es
The same thing happened to echoendoscopy or endoscopic ultrasonography (EUS). Color, sonoelastography, and contrast media have provided US with a new diagnostic and most particularly therapeutic dimension (2).

Color has made it possible to better study blood vessels (portal hypertension and growths).

Sonoelastography and contrast agents have attempted to improve diagnosis and avoid histological studies using fine needle aspiration puncture (FNA) (virtual biopsy) (Figs. 1 and 2).

However, what is the future of $\mathrm{CE}$ as applied to ultrasonography (CE-US) or endoscopic ultrasonography (CEEUS), including intraoperative ultrasonography (CE-IUS)?

The use of CE in these three diagnostic scenarios - US, EUS, IUS - is discussed below.

\section{FACT AND FUTURE OF CE-US}

The following indications are now a fact:

- Characterization, delimitation, and detection in the liver of hepatic masses in over $90 \%$ of patients (3$5)$; detection of masses in the spleen and pancreas (6).

- Diagnosis of portal hypertension and portal thrombosis (100\%), even if malignant (94\%).

- Differentiation between benign and malignant lesions in a percentage above $95 \%$ (7).

- Study of GI tract microcirculation: thrombosis, ischemia (8), and inflammatory bowel disease (IBD) (9).

- Ablative therapy control.

The future likely lies in these last two fields:

- Gene therapy

- Functional studies.

\section{FACT AND FUTURE OF CE-EUS}

There are no conclusive studies regarding the use of CE-EUS for adenopathies and the GI tract. 


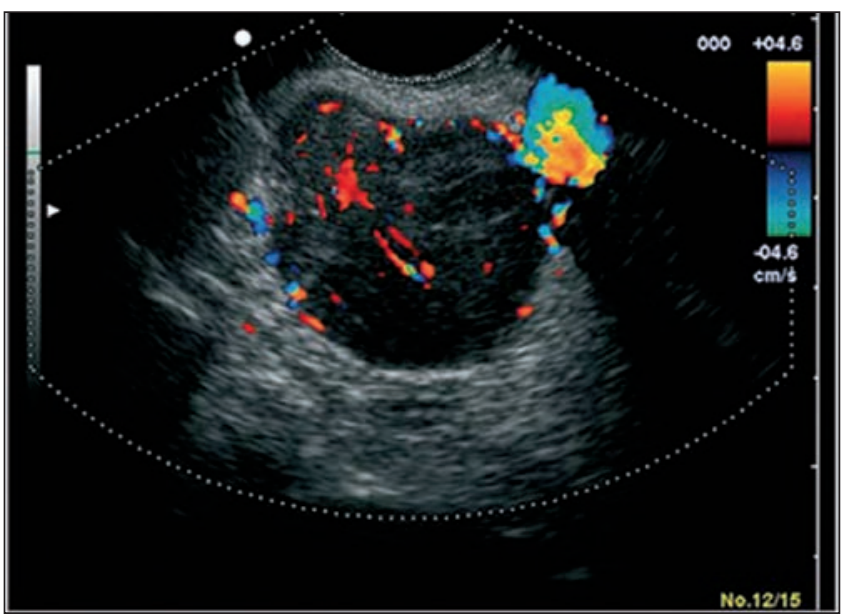

Fig. 1. Hypervascular neuroendocrine tumor (by courtesy of Dr. Dietrich) (2).

In the study of pancreatic conditions using CE-EUS pancreatic cancer (PC) detection - including smaller tumors (11) - is now a fact (10), but the differential diagnosis between adenocarcinoma and chronic nodular pancreatitis remains problematic.

Endoscopic retrograde cholangiography (ERC) and magnetic resonance cholangiography (MRC) have a sensitivity nearing $85 \%$, CT and EUS are above $90 \%$, and EUS-FNA reaches up to $95 \%$ (with a mean $86 \%$ that boils down to $54 \%$ in the presence of chronic pancreatitis) with a specificity of almost $100 \%$, whereas CE-EUS has a sensitivity of $93 \%$ and a specificity of nearly $100 \%$ $(94 \%)$.

What about EUS sonoelastograhy?

Most published papers on pancreatic masses show high sensitivity $(87 \%)$ and moderate specificity in differentiating benign from malignant lesions except for a recent report of low sensitivity and specificity in the diagnosis of even adenocarcinoma (50\%) that recommends FNA.

Recent papers $(12,13)$ in our country obtained a sensitivity of $100 \%$ and a specificity of 78 and $85 \%$. Therefore, this test may well obtain false positive but no false negative results, interestingly in contrast to EUS-FNA.

Neuroendocrine tumor (NET) detection with CE (Fig. 1) approaches $100 \%$ (14) (Giovanninni 7/8: 88\%), and the same occurs with NET metastases $(15,16)$. Therefore, it might be indicated for the detection of tumors in patients with multiple endocrine neoplasia (MEN) (small, multiple tumors).

\section{FACT AND FUTURE OF IUS AND CE-LAPUS}

It has been shown in 60 patients that $\mathrm{CE}$ is more sensitive that intraoperative US (IUS) for the detection of liver metastases, and modifies the management and resection with curative intent in $30 \%$ of patients (17).

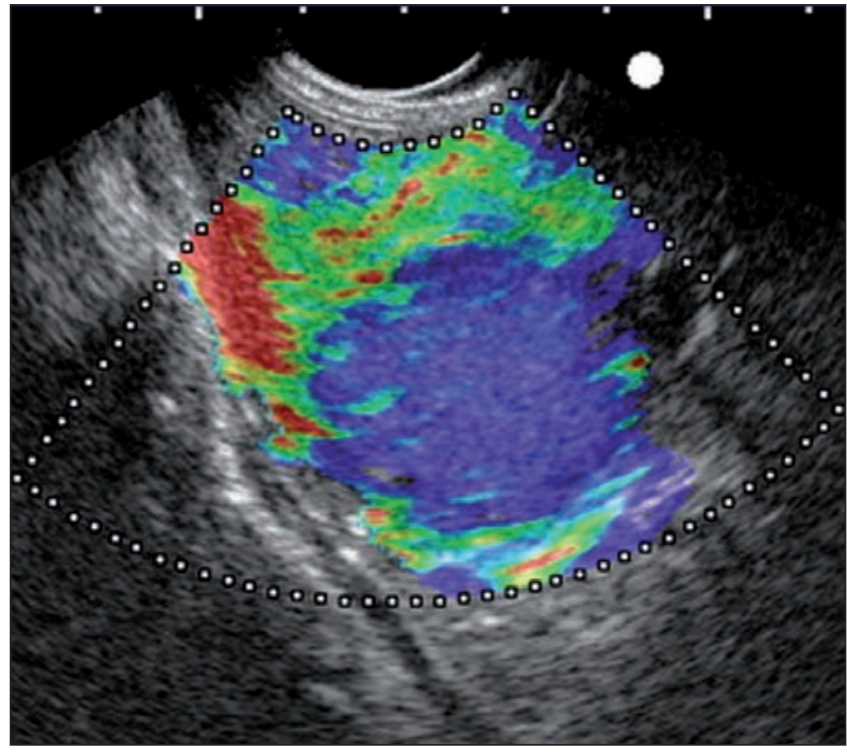

Fig. 2. Pancreatic cancer sonoelastogram (by courtesy of Dr. Giovannini).

Better results have also been obtained with CE-IUS versus IUS in the detection of 20 cases of hepatocarcinoma (HC) on liver cirrhosis (18).

The use of CE will be crucial prior to liver resection and probably pancreas resection in the future.

\section{FUTURE-RELATED CONCLUSIONS}

1. Detection of smaller HCs.

2. Ablative therapy control.

3. Detection of overlooked liver micrometastases, particularly from colon cancer.

4. Study of intestinal microcirculation (inflammation, ischemia, thrombosis).

5. Smaller NETs. MEN?

6. Differential diagnosis of PC versus $\mathrm{CP}$. Masses.

7. Contribution to liver and possibly pancreatic resection?

8. Gene therapy.

9. Gene therapy control.

10. Other, including functional studies, etc.

\section{ADDENDUM}

While CE is not licensed in some countries, its impact has been demonstrated (diagnosis in $90 \%$ with modification of patient management in 17.5 and $15.6 \%$, and up to $30 \%$ with CE-IUS) $(17,19,20)$, as well as its implementation cost-effectiveness.

Lacking ionizing radiation and with no renal toxicity in over 23,000 patients (scarce morbidity, no mortality) (21), the diagnostic information achieved is comparable to that of CT and MRI (22); for some authors (23) it 
Table I. References overview

EUS-Sonoelastography

\begin{tabular}{|c|c|c|c|c|c|c|}
\hline Giovannini (35) 2006: & 24 & pancreas g. (1 NET) & S: $100 \%$ & Sp: $67 \%$ & & \\
\hline Giovannini (2) 2008: & 121 & P: $89.2 \%$ & S: $80.6 \%$ & Sp: $92.3 \%$ & PPV: 93.3 & NPV: $78 \%$ \\
\hline Giovannini (36) 2009: & 121 & & S: $92.3 \%$ & Sp: $80 \%$ & & \\
\hline Janssen, 2007: & 7320 PC and 2 NET & P: 73.5 & S: 93.8 & Sp: $65.4 \%$ & PPV: 51.7 & NPV: 96.5 \\
\hline Deprez, 2007: & 187 PC, 3 NET, 6 CP & & S: $100 \%$ & Sp: $50 \%$ & PPV: 77 & NPV: 100 \\
\hline Saftoiu, 2007: & $7 \mathrm{PC}$ & P: $84.4 \%$ & S: $80 \%$ & Sp: $91.7 \%$ & PPV: 94.1 & NPV: 73.7 \\
\hline Hirche (37) 2008: & 70 c. $10 \mathrm{C}$. & $P: 45 \%$ & S: $41 \%$ & Sp: $53 \%$ & & \\
\hline Quites previous papers & 46 PC and 12 NET (100\%) & & & & & \\
\hline Saftoiu (38) 2008: & $32 P C, 11 C P, 3$ & P: $89.7 \%$ & S: $91.4 \%$ & Sp: $87.9 \%$ & PPV: 88.9 & NPV: 90.6 \\
\hline Iglesias (12) 2008: & $80 c, 10 c$ & P: $93.7 \%$ & S: $100 \%$ & Sp: 78.3\% & & \\
\hline Iglesias (13) 2009: & $130 c, 20 c$ & P: $94 \%$ & S: $100 \%$ & Sp: $85.5 \%$ & & \\
\hline Iglesias (43) 2010: & $86 \mathrm{C}(49 \mathrm{CP})$ & & S: $100 \%$ & Sp: $92.9 \%$ (6 NET) & & \\
\hline Mean & & P: $81 \%$ & S: $89 \%$ & Sp: $76 \%$ & PPV: $82 \%$ & NPV: $89 \%$ \\
\hline
\end{tabular}

even has enthralling future indications in the diagnosis and even treatment of digestive system conditions (2429).

Sonoelastography $(16,30-34)$ must improve in the future $\left(2^{\text {nd }}\right.$ or $3^{\text {rd }}$ generation) its sensitivity and specificity for pancreatic tumors, adenopathies, and submucosal tu- mors in order to compete with contrast media and FNA (Tables I and II).

A novel option would combine sonoelastography and contrast agents in the differential diagnosis between chronic pancreatitis and pancreatic cancer (40) with a gain in specificity and PPV (96\%) (Table III).

Table II. References overview

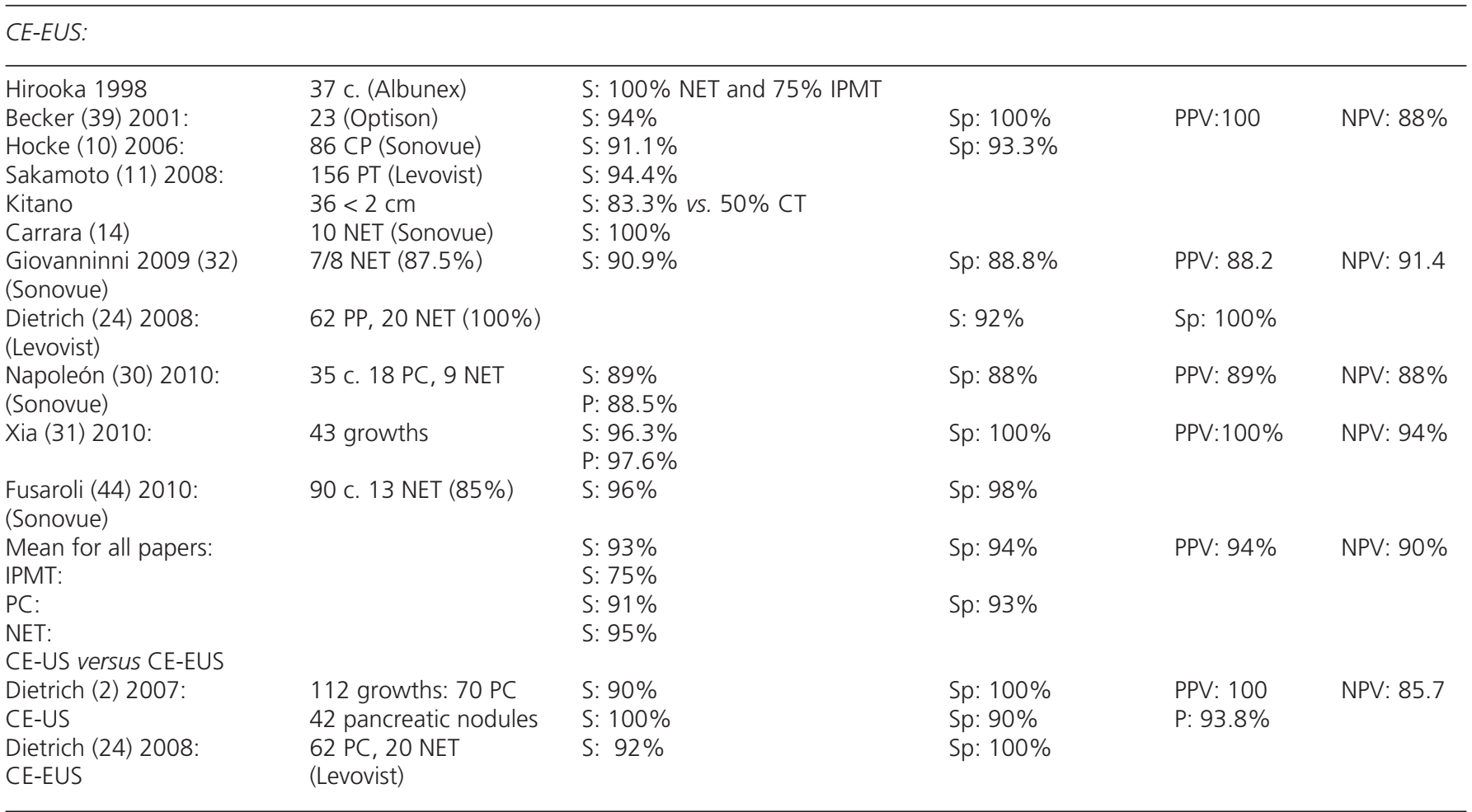


Table III. Algorithm

Diagnostic orientation:

Pancreatic tumor suspicious of PC by US/ EUS/ CT/ MRI (1st-line imaging techniques):

CT + EUS recommended, as well as CA 19.9 measurement

Possibilities:

Focal $\mathrm{CP}$ and related

Pseudotumor

Autoimmune disease

Tuberculoma

Lymphoma

Etc.

Diagnosis by 2nd-line imaging tests:

EUS-Sonoelastography

Contrasts (CE)

EUS-FNA

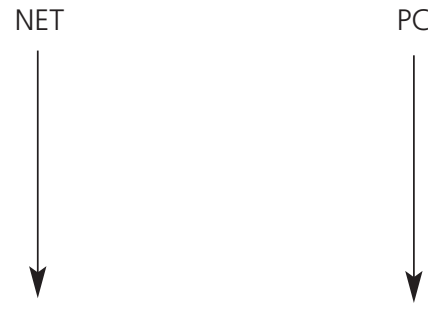

$<100 \%$ ?
$95 \%$
$90 \%$

Contrasts vs. EUS-S?
PC

S: $89 \%$

S: $92 \%$

S: $86 \%$

CE versus FNA

CE plus EUS-S

Staging and resectability:

EUS more than CT (2)

Non-resectability:

EUS-FNA if preoperative neoadjuvancy (41)

Modified and extended from references 2, 42, and 45. CP: chronic pancreatitis. PC: pancreatic cancer. NET: neuroendocrine tumor. C: control.

\section{REFERENCES}

1. Novedades en ultrasonidos. Rev Esp Enferm Dig 2007;99(Supl.II): 23-27,28-35.

2. Varas MJ. Ultrasonografía endoscópica, aplicaciones diagnósticas y terapéuticas. Madrid: Ed. Médica Panamericana; 2008.

3. Ding $\mathrm{H}$, Wang $\mathrm{W}$, Huang $\mathrm{B}$, et al. Imaging of focal liver lesions. Low-mechanical-index real-time ultrasonography with Sonovue. J Ultrasound Med 2005;24:285-97.

4. Forner A, Rodríguez de Lope C, Reig M, et al. Early diagnosis of primary liver cancer: imaging versus genetics. Rev Esp Enferm Dig 2008;100:423-9.

5. Piscaglia F, Corradi F, Mancini M, et al. Real time contrast enhanced ultrasonography in detection of liver metastases from gastrointestinal cancer. Cancer 2007;7:171-7.

6. Kitano M, Kudo M, Maekawa K, et al. Dynamic imaging of pancreatic diseases by contrast enhanced coded phase inversion harmonic ultrasonography. Gut 2004;53:854-9.

7. Celli N, Gaiani S, Piscaglia F, et al. Characterization of liver lesions by real-time contrast-enhanced ultrasonography. Eur J Gastroenterol Hepatol 2007;19:3-14.

8. Hamada T, Yamauchi M, Tanaka M, et al. Prospective evaluation of contrast-enhanced ultrasonography with advanced dynamic flow for the diagnosis of intestinal ischaemia. B J Radiology 2007;80:603-8.

9. Migaleddu V, Scanu AM, Quaia E, et al. Contrast-enhanced ultrasonography evaluation of inflammatory activity in Crohn's disease. Gastroenterology 2009;137:42-52.

10. Hocke M, Schulze E, Gottschalk P, et al. Contrast-enhanced endoscopic ultrasound in discrimination between focal pancreatitis and pancreatic cancer. W J Gastroenterol 2006;12:246-50.

11. Sakamoto H, Kitano M, Suetomi Y, et al. Utility of contrast-enhanced endoscopic ultrasonography for diagnosis of small pancreatic carcinomas. Ultrasound Med Biol 2008;34:525-32.

12. Iglesias-Garcia J, Lariño-Noia J, Domínguez-Muñoz JE. Endoscopic ultrasound elastography in the differential diagnosis of pancreatic so- lid masses: towards the virtual biopsy. Gastroenterology 2008;134 (Supl.1):A-47.

13. Iglesias J, Lariño J, Adbulkader I, et al. EUS elastography for the characterization of solid pancreatic masses. Gastrointest Endosc 2009;70:1101-8

14. Carrara S, Arcidiacono PG, Mezzi G, et al. Contrast-enhanced endoscopic ultrasound (CE-EUS) in the evaluation of pancreatic masses JOP. J Pancreas (Online) 2006;7(Supl. 5):558.

15. Malagò R, D’Onofrio M, Zamboni GA, et al. Contrast-enhanced sonography of nonfunctioning pancreatic neuroendocrine tumors. AJR 2009:192:424-30.

16. Dietrich CF. Contrast-enhanced low mechanical index endoscopic ultrasound (CELMI-EUS). Endoscopy 2009;41:E43-E-44.

17. Leen E, Ceccotti P, Moug SJ, et al. Potential value of contrast-enhanced intraoperative ultrasonography during partial hepatectomy for metastases: an essential investigation before resection? Ann Surg 2006;243:236-40.

18. Lu Q, Luo Y, Yuan CX, et al. Value of contrast-enhanced intraoperative ultrasound in surgery for hepatocellular carcinoma in cirrhosis: 20 cases report. World J Gastroenterol 2008;14:4005-10.

19. Tombesi P, Catellani M, Abbasciano V, et al. Impact of contrast-enhanced ultrasonography in a tertiary clinical practice. J Ultrasound Med 2008;27:991-2.

20. Lanka B, Jang H-J, Kim TK, et al. Impact of contrast-enhanced ultrasonography in a tertiary clinical practice. J Ultrasound Med 2007;26:1703-14.

21. Piscaglia F, Bolondi L. The safety of SonoVue in abdominal applications: retrospective analysis of 23.188 investigations. Ultrasound Med Biol 2006;32:1369-75.

22. Wilson SR, Greenbaum LD, Goldberg BB. Contrast-enhanced ultrasound: GAT is the evidence and what are the obstacles? AJR 2009; 193:55-60

23. Trillaud H, Bruel JM, Valente PJ, et al. Characterization of focal liver lesions with Sonovue R-enhanced sonography: International multicenter-study in comparison to CT and MRI. World J Gastroenterol 2009:15:3748-56 
24. Dietrich CF, Ignee A, Braden B, et al. Improved differentiation of pancreatic tumors using contrast-enhanced endoscopic ultrasound. Clin Gastroenterol Hepatol 2008;6:590-7.

25. Klibanov A. Microbubble contrast agents: targeted ultrasound imaging and ultrasoun-assisted drug-delivery applications. Investigate Radiology 2006;41:354-62.

26. Hernot S, Klibanov AL. Microbubbles in ultrasound-triggered drug and gene delivery. Adv Drug Deliv Rev 2008;60:1153-66.

27. Bhutani MS. Digital analysis of EUS images: "promising" meted, but is it ready for "prime time" ? Gastrointest Endosc 2008;67:868-70.

28. Ho K-Y. Advanced imaging options: what is available? Gastrointest Endosc 2009;69(2):S68-S70.

29. Álvarez MV, Varadarajulu S, Napoleón B. EUS contrast agents: what is available, how do they work, and are they effective? Gastrointest Endosc 2009;69(2):S71-S77.

30. Napoleon B, Alvarez MV, Gincoul R, et al. Contrast-enhanced harmonic endoscopic ultrasound in solid lesions of the pancreas: results of a pilot study. Endoscopy 2010;42:564-70.

31. Xia Y, Kitano M, Kudo M, et al. Characterization of intra-abdominal lesions of undetermined origin by contrast-enhanced harmonic EUS. Gastrointest Endosc 2010;72:637-42.

32. Giovannini M. Contrast-enhanced endoscopic ultrasound and elastosonoendoscopy. Best Practice and Research Clin Gastroenterol 2009; 23:767-79.

33. Hirooka Y, Itoh A, Kawashima H, et al. Diagnosis of pancreatic disorders using contrast-enhanced EUS and endoscopy elastotography. Clin Gastroenterol Hepatol 2009; 7:S63-S67.

34. Iglesias García J, Lariño Noia J, Álvarez Castro A, et al. Second-generation endoscopic ultrasound elastography in the differential diagnosis of solid pancreatic masses. Pancreatic cancer vs inflammatory mass in chronic pancreatitis. Rev esp Enferm Dig 2009;101:723-30

35. Giovannini M, Hookey LC, Bories E, et al. Endoscopic ultrasound elastography: the first sep towards virtual biopsy? Preliminary results in 49 patients. Endoscopy 2006;38:344-8.
36. Giovannini M, Thomas B, Erwan B, et al. Endoscopic ultrasound elastography for evaluation of lymph nodes and pancreatic masses: a multicenter study. World J Gastroenterol 2009;15:1587-93.

37. Hirche TO, Ignee A, Barrerios AP, et al. Indications and limitations of endoscopic ultrasound elastography for evaluation of focal pancreatic lesions. Endoscopy 2008;40:910-7.

38. Saftoiu A, Vilmann P, Gorunescu F, et al. Neural network analysis of dinamic sequences of EUS elastography used the differential diagnosis of chronic pancreatitis and pancreatic cancer. Gastrointest Endosc 2008;68:1086-94.

39. Becker D, Strobel D, Bernatik T, et al. Echo-enhanced color and power-Doppler EUS for discrimination between focal pancreatitis and pancreatic carcinoma. Gastrointest Endosc 2001;53:784-9.

40. Saftoiu A, Iordache SA, Gheones DI, et al. Combined contrast-enhanced power doppler and real time sonoelastography performed during EUS, used in the differential diagnosis of focal pancreatic masses. Gastrointest Endosc 2010;72:739-42.

41. Iglesias García J, Lariño Noia J, Domínguez Muñoz JE. Endoscopic ultrasound in the diagnosis and staging of pancreatic cancer. Rev Esp Enferm Dig 2009;101:631-8.

42. Helmstaedter L, Riemann JF. Pancreatic cancer-EUS and early diagnosis. Langenbecks Arch Surg 2008;393:923-7.

43. Iglesias Garcia J, Lariño Noia J, Abdulkader I, Forteza J, Domínguez Muñoz JE. Quantitative endoscopic ultrasound elastography: an achurate method for the differentiation of solid pancreatic masses Gastroenterology 2010; 139: 1172-80

44. Fusaroli P, Spada A, Mancino MG, Caletti G. Contrast harmonic Echo-Endoscopic ultrasound improves accuracy in diagnosis of solid pancreatic masses. Clin Gastroenterol Hepatol 2010; 8: 62934.

45. Reddy NK, Ioncica AM, Sàtoiu A, Vilmann P, Bhutani MS. Contrast-enhanced endoscopic ultrasonography. World J Gastroenterol 2011;17:42-8. 